\title{
Guy Structure with Galvanic Corrosion: Case Study
}

Romildo Alves Berenguer ${ }^{1}$, Edmilson Raimundo de Oliveira Júnior ${ }^{1}$, Marcus Wagner Pereira da Silva ${ }^{1}$, Glauber Beirão de Souza ${ }^{1}$, Paulo Helene ${ }^{3}$ and Eliana Cristina Barreto Monteiro ${ }^{1,2}$

1. Department of Civil Engineering, University of Pernambuco, Recife 51110-200, Brazil

2. Department of Civil Engineering, Catholic University of Pernambuco, Recife 51110-200, Brazil

3. Ph.D.-Engenharia, Department of Civil Engineering, Street Viscount in Black Gold, São Paulo 01303-060, Brazil

\begin{abstract}
Reinforcement bar corrosion depends heavily on environment and the processes used. This study will address galvanic corrosion. Based on a case study of galvanic corrosion in a guyed power transmission tower, experiments using a number of methods were made on a small sample of eight poles chosen for excavation and visual inspection, to assess the various resulting diagnoses. Method that provided the best results both in location and classification of the points was adopted, where corrosion had already begun, considering the concern of finding a non-evasive process. To diagnose the status of the poles inserted in rock, after applying the methods, the main types of corrosion affecting them were listed and classified. With the results, the possible means of preventing and maintaining the structure were presented.
\end{abstract}

Key words: Corrosion, diagnosis, inspection.

\section{Introduction}

Corrosion is a destructive process relating to practically all sectors of human activity. Even in areas such as medicine and odontology, which use metal implants and different metal alloys to restore teeth, the problems of corrosion are serious. To stress the economic importance of corrosion, Table 1 lists several cost estimates of corrosion in different countries. These data show that corrosion costs countries an annual $3 \% \sim 4 \%$ or so of their GNP (gross national product) and that around $20 \%$ of these costs could be prevented. According to the cost estimates of corrosion shown in Table 1, it is essential to learn even more information on the topic in the technical environment and consequently somehow minimise the resulting effects.

In order to present a case study on galvanic corrosion and on the main anti-corrosion solutions, the study herein undertook comprehensive research on

Corresponding author: Romildo Alves Berenguer, professor, research fields: concrete, corrosion materials and structural concrete. galvanic corrosion in a guyed power transmission line system.

\section{Methodology}

The first stage of the study was to identify which type of corrosion originated in the structure, and then present the principles of the corrosion type installed therein. Lastly, it addressed the results from tests and the possible means of prevention and maintenance of the structure.

\section{Case Study}

The structures in question are guyed metal lattice power transmission towers VX6 for suspension insulator strings. The guaranteed stability of the power line structures is linked to maintaining the technical characteristics of their components' strength. When dealing with VX6 power transmission towers, bracing is essential for this condition. Hence the guy cables transfer their forces to the foundation elements, which can be caissons moulded on site or anchored in rock. The caisson solution consists of unreinforced concrete elements moulded in-situ in the shape of a 
truncated cone to which the anchors are fixed. The rock-anchor solution consists of fixing the anchors directly to solid rock. The guys are fixed to the ground using galvanised steel poles encased in a PVC (polyvinyl chloride) pipe, filled with cement paste throughout.

Table 1 Cost estimates of corrosion in various countries [4].

\begin{tabular}{lllll}
\hline Country & Year & Cost (USD billion) & GNP (\%) & Avoidable (\%) \\
\hline India & $1960 \sim 1961$ & 0.32 & - & - \\
West Germany & $1968 \sim 1969$ & 6.00 & 3.0 & 25 \\
Ex-USSR & $1969 \sim 1969$ & 6.70 & 2.0 & - \\
United Kingdom & $1969 \sim 1970$ & 3.20 & 3.5 & 23 \\
Australia & $1973 \sim 1973$ & 0.55 & 1.5 & - \\
Japan & $1976 \sim 1977$ & 9.20 & 1.8 & - \\
USA & $1975 \sim 1975$ & 70.0 & 4.2 & 15 \\
\hline
\end{tabular}

Note: USSR - Union of Soviet Socialist Republics.

The pole was inserted directly into a rock where it exists to a depth of $1.80 \mathrm{~m}$, limiting the use of the PVC pipe only to the part of the pole outside the consolidated material, as shown in Figs. 1 and 2 . Plastic spacers were used to ensure the coating of the bar with cement paste. With such care it was intended to ensure perfect separation of the metal element from the ground, and therefore, to prevent installation of the corrosion process, worsened in this project by using counterweight wires in copper-coated steel, inserted in the same electrolytic medium and connected to the poles at a point above ground. Considering the two failures of poles due to galvanic corrosion, the guaranteed insulation of their coating was stopped and hence the need for inspections.

When metal lattice structures are used consisting of galvanised steel profiles, normally the conservation status of the lattice is followed up with periodic visual inspections. In the overhead part of the structures, inspections and corrections of any abnormalities are relatively easy. On the other hand, inspections of underground parts are not so simple, since they require further measures to ensure stability of the structures during the excavation process. When damage caused to a foundation is detected, it generally implies their substitution. In the Teresina II Sobral III and Sobral III Fortaleza II power lines, both energised at $500 \mathrm{KV}$, typical guyed structures type VX6 were implemented, with four guys each as shown in Fig. 3. Caisson foundations and rock-anchored foundations were used as traction supports. The caisson solution comprises unreinforced concrete elements moulded in-situ in the shape of a truncated cone, to which the anchors are fixed as shown in Fig. 4. The rock anchor solution consists of fixing the anchors directly to the solid rock. These guys are fixed to the ground using galvanised steel poles encased in a PVC pipe, filled with cement paste throughout. Plastic spacers were used to ensure that the bar is covered with cement paste. This care was designed to ensure that the metal element was perfectly

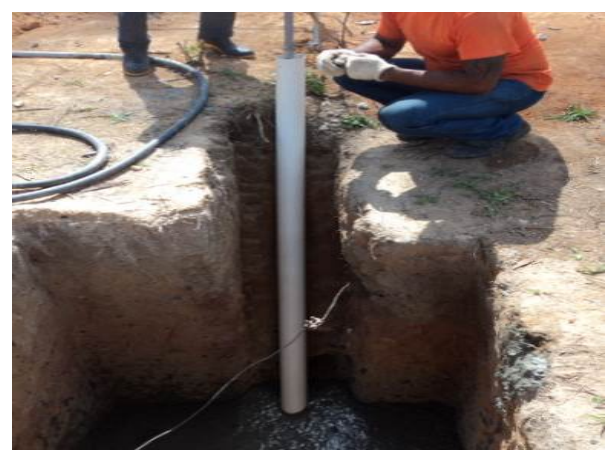

Fig. 1 Pole encased in a PVC pipe.

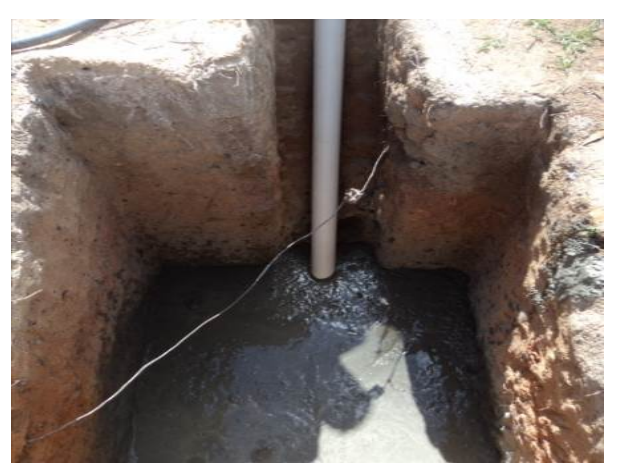

Fig. 2 Detail for application of the PVC pipe. 


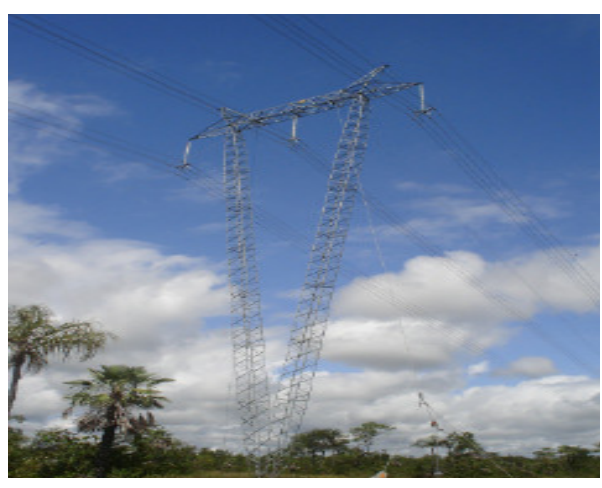

Fig. 3 Guyed tower VX6.

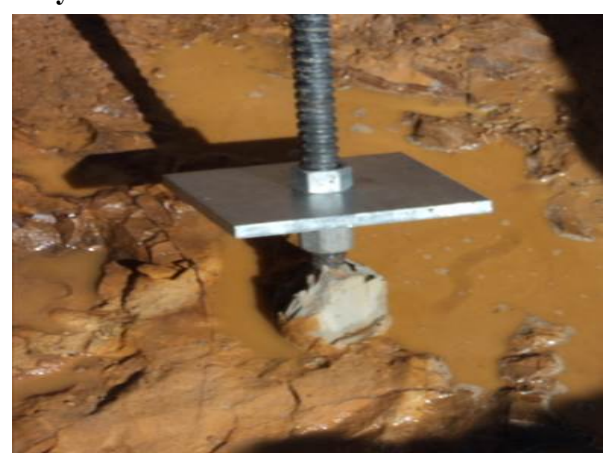

Fig. 4 Anchoring the guy pole.

separated from the ground.

The ground's physical-chemical characteristics might allow the formation of an electrolyte that could become aggressive to metal elements submerged therein. On the other hand, the power lines are so-called linear structures characterised by their length.

Therefore, their foundations are installed in a continuous strip of land characterised by very heterogeneous ground. This heterogeneity includes characteristics of electrical resistivity, $\mathrm{pH}$, water retaining capacity, aeration, total acidity, alkalinity, chloride content, sulphates, sulphides and bacteria. Such characteristics are responsible for the soil's greater or lesser aggressiveness. Even considering a metal element with no heterogeneity, when it is buried through layers of soil with different resistivity, it may lose its homogeneity in cathode and anode regions. Corrosion specialists [2, 3] indicate three basic situations of corrosion in the soil that might possibly occur simultaneously: (1) corrosion by bacteria; (2) corrosion by leakage currents and (3) galvanic corrosion:
- corrosion by bacteria: a special situation occurring when chemical reactions of corrosion are produced, resulting from the high incidence of certain microorganisms;

- corrosion by leakage current: parasite currents created by systems of electrical traction or direct current transmission systems that cause corrosion by electrolysis from buried metal elements;

- galvanic corrosion: two underground metals considered as an electrolyte, operating as anode and cathode in the presence of an electrical current circulating between them, as shown in Fig. 5.

Project details and construction procedures associated with the natural aggressiveness of soils could contribute to the appearance of corrosion in the guy foundations. The authors know a number of cases of this kind in other power lines in Brazil. When a construction defect occurs in the layer formed by the cement paste, the stretch of pole with vulnerable coating comes in contact with the favourable electrolytic medium. Conditions of a potentially active galvanic cell arise, able to accelerate the wear of the unprotected part of the anchor as shown in Figs. 6 and 7, due to the established difference in potential. Depending on the gravity of the parameters, the phenomenon can cause the early failure of the pole by local corrosion.

\subsection{Inspection}

Visual inspection of the poles embedded in the rock incurs very high cost. Their full excavation

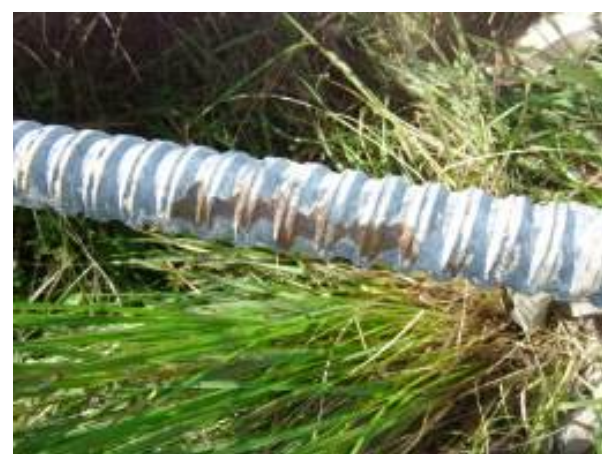

Fig. 5 Detail of failure in zinc protection and start of the corrosion process. 


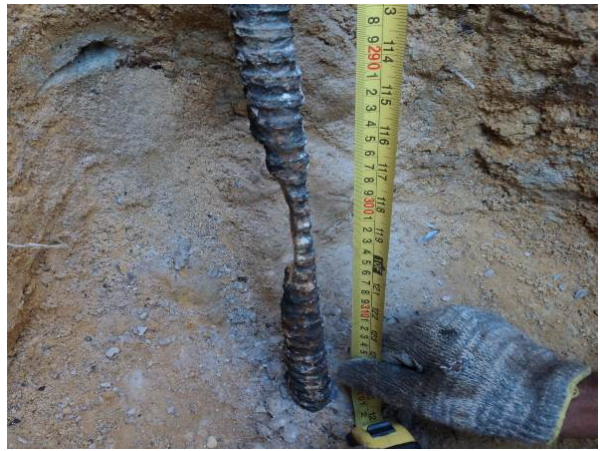

Fig. 6 Detail of severe local corrosion at the depth of occurrence.

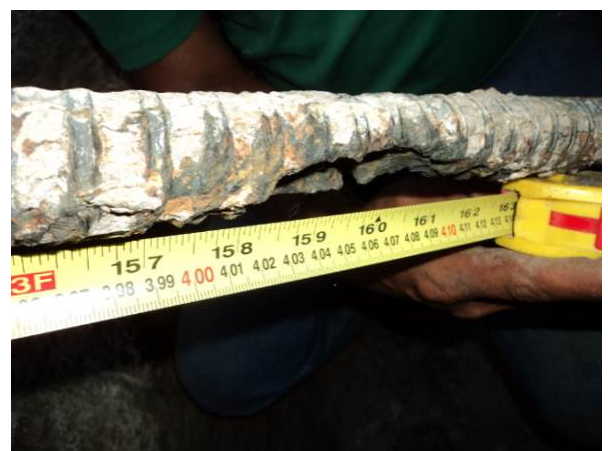

Fig. 7 Detail of severe corrosion caused by the galvanic cell at a considerable depth.

irredeemably damages the fixture, requiring another solution to be adopted for this foundation. So it is extremely important to find a safe process with compatible cost that provides a reliable diagnosis on the status of the embedded poles, locating their possible damage without needing excavations for direct visual inspections. Experiments were made on a small sample of eight poles, chosen for excavation and visual inspection in order to assess the resulting diagnoses. Method in Ref. [1] was adopted, which had the best results in finding a non-evasive process for the diagnosis of the status of the poles in the rock, both in location and classification of the points where corrosion had already begun.

In this case, the chosen method was originally developed to detect pathologies in active reinforcement bars. This technology is being used on a large scale in Europe for over 20 years. This principle was refined in the 1990s by a consortium of Swiss and Italian companies. In Brazil, it has been used since the mid-1990s to sound and monitor pre-stressed cables and stay bolts. Later, this method was applied to power line guy poles. Today, with the equipment and software available, it is possible to detect, gauge and locate pathologies in pre-stressed cables and stays with an error tolerance of $8 \%$.

Much information can be collected using the characteristics of an electrical impulse. The method [1] is a non-destructive electronic test process based on TDR (time domain reflectometry). It consists of sending a high frequency signal along the metal element and interpreting its behaviour by the signal's response. The signal used is a very short electrical impulse emitted in wave format and known ranges. After being captured on its return to the transmitter, it is then analysed. For example, an impulse of an extremely short sinusoidal voltage $(2 \eta \mathrm{s} \sim 2 \mu \mathrm{s})$ is applied to the end of a pre-stressed steel bar. Apparatus is connected to the steel element to be tested. The signal is issued and captured by a benchmark wire called an antenna. The signal is interpreted in order to locate, qualify and gauge any anomalies or pathologies present in the steel (corrosion). 12 tests were performed to assess single foundation bars anchored in rock for guys, all located in the $\mathrm{TL}$ (transmission lines) $500 \mathrm{KV}$ Teresina II $\sim$ Sobral III-C2. At this stage, a steel bar was used to gauge the system. In August 2008, another batch of RIMT (reflectrometric impulse measurement technique) tests was run to assess integrity of single bars of guyed foundation as shown in Fig. 8, located in the TL $500 \mathrm{KV}$ Teresina II Sobral III and TL 500

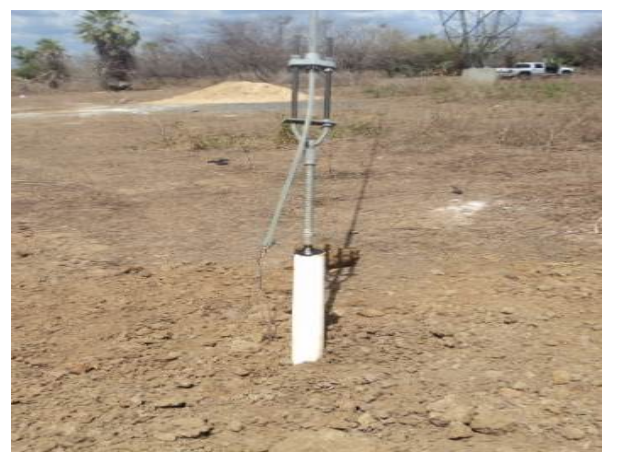

Fig. 8 Detail of the guy ready for the second assessment stage. 
Table 2 Gauging corrosion.

\begin{tabular}{|l|l|l|l|}
\hline Attributes & Grade & Qualification & To do \\
\hline $\begin{array}{l}\text { Loss of protective surface; } \\
\text { Very superficial and widespread oxidation }\end{array}$ & 01 & $\begin{array}{l}\text { Irrelevant anomaly; } \\
\text { No reduction in usable section }\end{array}$ & No applicable intervention \\
\hline $\begin{array}{l}\text { Slight localised oxidation; } \\
\text { Sparse zones of corrosion }\end{array}$ & 02 & $\begin{array}{l}\text { Slight anomaly; } \\
\text { Formation of surface oxide layer }\end{array}$ & $\begin{array}{l}\text { Check development; } \\
\text { Averagely 1 2 years }\end{array}$ \\
\hline $\begin{array}{l}\text { More relevant oxidation points in depth } \\
\text { and extent }\end{array}$ & 03 & $\begin{array}{l}\text { Average anomaly; } \\
\text { Slight reduction in steel section }\end{array}$ & $\begin{array}{l}\text { Check development; } \\
\text { Every 6 or 12 months }\end{array}$ \\
\hline $\begin{array}{l}\text { Widespread corrosion presents formation } \\
\text { of surface crust }\end{array}$ & 04 & Relevant reduction in usable steel section & $\begin{array}{l}\text { Check development; } \\
\text { Monthly reviews }\end{array}$ \\
\hline $\begin{array}{l}\text { Strong corrosion with presence of notably } \\
\text { relevant crust }\end{array}$ & 05 & $\begin{array}{l}\text { Reduction in usable section; } \\
\text { Damage to functionality }\end{array}$ & $\begin{array}{l}\text { Check gravity; } \\
\text { Complementary methods }\end{array}$ \\
\hline $\begin{array}{l}\text { Failure of pole due to corrosion or } \\
\text { mechanical damage }\end{array}$ & 06 & Total reduction in usable section of cable & Replacement or reinforcement \\
\hline
\end{tabular}

KV Sobral III Fortaleza II-C2. Some poles tested in the first stage were retested. We will consider as an example the results obtained in the foundation anchor bar-that of Tower 62/2. Both the stretch above ground (outside and inside the PVC pipe) and the underground stretch, with their characteristics in relation to the dielectric are considered. The average velocity of the signal is $14 \sim 15 \mathrm{~cm} / \eta \mathrm{s}$.

\section{Discussing the Results}

The results from testing the $500 \mathrm{KV}$ Teresina II Sobral III Fortaleza II transmission line are indicated below and oriented according to Table 2:

- In the first batch of tests a total of 15 bars were analysed and some degree of anomaly was noted in them all:

- 10 bars indicate Grade 3 of corrosion;

- 13 bars indicate Grade 2 of corrosion;

- 3 bars indicate Grade 1 of corrosion;

- 14 bars indicate 1 corrosion areas;

- 1 bar indicates 1 corrosion area.

- In the second batch of tests a total of 42 bars were analysed, in which $100 \%$ had some degree of anomaly:

- 24 bars indicate Grade 1 of corrosion, i.e., 57\% of all tested;

- 41 bars indicate Grade 2 of corrosion, i.e., 97.6\% of all tested;

- 4 bars indicate Grade 3 of corrosion, i.e., 9.5\% of all tested;
- 40 bars (95\% of all tested) indicated more than one zone with anomaly.

To validate the results of the RIMT tests, eight guys were excavated with the removal of the PVC and cement paste. After the inspections, these foundations were recovered incurring an average cost of BRL 20,000.00 per foundation. This means that the cost of each RIMT test is only around $5 \%$ of the cost of the inspections (excavation + recovery), since after the removal of the rock it was not possible to use them again, under the characteristics of the previous design. Considering traditional test methods, the method [1] still indicates the following benefits:

(1) It is a non-destructive method: It only needs an electrical contact with the linear conductor;

(2) It is a fast efficient method: The portable equipment performs up to 100 tests in just one day on cables of up to $100 \mathrm{~m}$;

(3) It is used to monitor for the purpose of future preventive maintenance: The simple installation of electrical connections in the cables helps to follow up the phenomenon (located in earlier tests) during their working life, viewing their development in due time.

\section{Conclusions}

The structures comprising a power line, according to the conditions imposed by prevailing standards, must meet the minimum requirements of quality, which comprise failure safety, service performance 
and ability to satisfactorily withstand the influences of foreseen environmental and designed services.

At first the presence of anomalies hinders their performance and may even reach the stage that compromises the safety of the structures. Therefore, inspection and detection of failures in their elements are key activities to meet the aforementioned requirements.

Therefore, this paper was based on the case study of galvanic corrosion in guyed elements of power transmission towers, jeopardising their stabilities. Consequently, ongoing inspection work is carried out on the structures in order to guarantee the satisfactory role for which they were designed.

It should be mentioned that maintenance services are of the utmost importance for the working life of the structures, and that the technologies applied are very relevant, principally with regard to costs.

\section{References}

[1] Fontan, M. A. B. 2009. "Método para Avaliação da Corrosão de Tirantes em Rocha." Presented at Décimo Tercer Encuentro Regional Iberoamericano de Cigré-Xiii Eriac, Puerto Iguazú, Argentina. (in Portuguese)

[2] Ribeiro, D. V., and Helene, P. 2014. Corrosão em Estruturas de Concreto Armado. Teoria, Controle e Métodos de Análise (Corrosion in Reinforced Concrete Structures. Theory, Control and Methods of Analysis). Rio de Janeiro: Campus Publishers. (in Portuguese)

[3] Gentil, V. 2011. Corrosão (Corrosion). 6th ed. Rio de Janeiro: UFRJ (Universidade Federal do Rio de Janeiro) Afiliada Publishers. (in Portuguese)

[4] Gentil, V. 1996. Corrosão (Corrosion). 3rd ed. Rio de Janeiro: UFRJ Afiliada Publishers. (in Portuguese) 